\title{
A ideologia da contrarreforma do direito coletivo do trabalho e a contribuição do princípio da boa-fé para as negociações coletivas
}

The ideology of the counter-reform of collective labor law and the contribution of the principle of good faith to collective negotiations

\author{
Ana Maria Maximiliano \\ Universidade Federal do Paraná, Curitiba, Paraná, Brasil \\ Isabel Ceccon Iantas \\ Universidade Federal do Paraná, Curitiba, Paraná, Brasil
}

\begin{abstract}
Resumo: O presente artigo objetiva identificar a possível contribuição do princípio da boa-fé na construção das cláusulas que compõem o Acordo Coletivo do Trabalho (ACT) e a Convenção Coletiva do Trabalho (CCT). Para tanto, aponta a influência da ideologia, no contexto do neoliberalismo, na construção do direito do trabalho para, após, demonstrar o reflexo dessa ideologia na contrarreforma trabalhista, trazida pela lei no $13.467 / 2017$, que desregulamentou e flexibilizou os direitos trabalhistas. No contexto da contrarreforma, observa-se o enfraquecimento do direito coletivo do trabalho, acompanhado da desarticulação do movimento sindical, que abre a possibilidade de livre negociação com os sindicatos em uma posição de fragilidade negocial. Por fim, passa a expor o princípio da boa-fé em relação com o direito coletivo. Para o desenvolvimento, parte-se de pesquisa exploratória e abordagem qualitativa, com levantamento bibliográfico e pesquisa documental. Conclui-se que o princípio da boa-fé pode ser aplicado na formulação de acordos e convenções coletivas de trabalho, com o objetivo de proteger a classe trabalhadora.
\end{abstract}

Palavras-chave: contrarreforma trabalhista; direito coletivo do trabalho; ideologia; princípio da boa-fé.

Abstract: This article aims to identify the possible contribution of the principle of good faith in the construction of the clauses that make up the Collective Labor Agreement (CLA) and the Collective Labor Convention (CLC). Therefore, it points to the influence of ideology, in the context of neoliberalism, in the construction of labor law to, after, 
demonstrate the reflection of this ideology in the labor counter-reform, brought by law $\mathrm{n}^{\mathrm{o}}$ 13.467/2017, which deregulated and made labor rights more flexible. In the context of counter-reform, there is a weakening of collective labor law, accompanied by the disarticulation of the union movement, which opens up the possibility of free negotiation with unions in a position of bargaining weakness. Finally, it begins to expose the principle of good faith in relation to collective law. For development, it starts with exploratory research and a qualitative approach, with bibliographic survey and documentary research. It is concluded that the principle of good faith can be applied in the formulation of collective labor agreements and conventions, with the objective of protecting the working class.

Keywords: labor counter-reform; collective labor law; ideology; principle of good faith.

Sumário: 1. Introdução; 2. A ideologia do direito do trabalho; 3. A contrarreforma trabalhista e o direito coletivo do trabalho; 4 . O princípio da boa-fé e a aplicação no direito coletivo do trabalho; 5 . Considerações finais.

\section{Introdução}

A construção de uma legislação específica, que estabelece direitos e deveres tanto para o patronato quanto para o operariado, ocorre em um modelo específico de economia. Por isso, não é possível traçar uma história universal do surgimento do direito do trabalho. Ele surge e é codificado diante da consolidação do modo de produção capitalista, constituído por um conflito social próprio e característico: a inconciliabilidade de interesses entre as classes burguesa e trabalhadora.

Nas relações de emprego, em diferentes momentos históricos, está enraizado o conflito social, de forma que a regulamentação se fez imprescindível para a manutenção de uma sociedade pautada pelas trocas de valores. Por ser uma área de conflitos constantes, as ideologias e a política têm um importante papel no momento da construção do direito do trabalho, bem como na celebração dos Acordos Coletivos de Trabalho (ACT) e Convenções Coletivas de Trabalho (CCT). Com relação ao direito do trabalho, a ideologia e a política refletem a composição da legislatura, que atuará na produção e na alteração das leis. Já com relação ao ACT e à CCT, o reflexo da ideologia e da política ocorrem na composição da instituição sindical.

A par da política e da ideologia, soma-se o contexto neoliberal, que visa a intervenção mínima do Estado na economia e, por isso, busca de 
forma constante a desregulamentação e flexibilização de direitos trabalhistas, bem como a mitigação de princípios estruturantes do direito do trabalho ${ }^{1}$. Com isso, ocorre o paulatino enfraquecimento das proteções aos trabalhadores e à atuação sindical.

Isso pode ser observado na contrarreforma trabalhista ${ }^{2}$, que, além de retirar direitos da classe trabalhadora, alterou premissas garantidoras da liberdade sindical. Assim, o direito coletivo do trabalho foi também afetado pelas mudanças no tocante às negociações coletivas e à própria organização e articulação dos sindicatos.

Com relação ao direito coletivo do trabalho, as alterações mais radicais foram a extinção de contrapartidas recíprocas para a celebração de ACT e CCT, em conjunto com a mitigação da fonte de custeio dos sindicatos ao se dificultar a contribuição sindical pelos trabalhadores. Isso porque a contrarreforma se consolidou em um contexto de políticas de cunho neoliberal e de uma ideologia marcada pela pretensão de descoletivização das relações de trabalho.

Diante do recrudescimento do ataque ao direito coletivo do trabalho, deve-se recorrer aos princípios que norteiam o direito, notadamente o princípio da boa-fé na perspectiva da celebração de ACT e CCT. Muito embora a contrarreforma trabalhista tenha afastado a exigência de contrapartidas nesses ajustes coletivos, o princípio da boa-fé, como balizador estruturante para a celebração dos contratos, deve ser considerado no direito coletivo do trabalho.

Dessa forma, em meio às buscas por mecanismos de proteção para o trabalhador, notadamente no contexto do direito coletivo do trabalho, o artigo objetiva identificar a possível contribuição do princípio da boa-fé na construção das cláusulas que compõem o Acordo Coletivo do Trabalho (ACT) e a Convenção Coletiva do Trabalho (CCT). Para tanto, aponta a influência da ideologia, no contexto do neoliberalismo, na construção do

\footnotetext{
1 Para Plá Rodriguez (2015), os princípios basilares do direito do trabalho são o princípio da proteção, a irrenunciabilidade dos direitos trabalhistas, a continuidade do contrato de trabalho, a primazia da realidade e a boa-fé.

${ }^{2}$ Utiliza-se o termo "Contrarreforma" tendo em vista que a Lei 13.467/2017 não trouxe uma efetiva "reforma" da Consolidação das Leis Trabalhistas, mas, em contrapartida, reverteu o processo de construção da Legislação Trabalhista, contrariando suas premissas protetivas (GHIRALDELLI, 2019).
} 
direito do trabalho para, após, demonstrar o reflexo dessa ideologia na contrarreforma trabalhista. Por fim, expõe o princípio da boa-fé em relação ao direito coletivo. Para o desenvolvimento, parte-se de pesquisa exploratória e abordagem qualitativa, com levantamento bibliográfico e pesquisa documental.

\section{A ideologia do direito do trabalho}

A consolidação do modo de produção capitalista, no final do século XVIII, fez surgir um novo antagonismo social, que superou as antigas relações feudais. Assim, de um lado estava a burguesia, detentora de capital e, por conseguinte, dos meios de produção e circulação de mercadorias, e, de outro, a classe trabalhadora, que, por não possuir bens suficientes, passou a vender a sua força de trabalho em troca de um salário para a própria subsistência.

A relação estabelecida entre a classe proprietária dos modos de produção e a classe trabalhadora, denominada de relação de trabalho, no entanto, é caracterizada pela inconciliabilidade entre os interesses dessas classes. Enquanto uma, a classe proprietária, visa cada vez mais expandir o seu capital, por meio da ideia de lucro, a outra, a classe trabalhadora, busca receber o equivalente entre o tempo e a força despendidos e o salário auferido. Em outras palavras, para que o capitalista possa aumentar a sua lucratividade, necessariamente precisa explorar ao máximo a força de trabalho de seus trabalhadores (MARX, 1985).

A relação entre o proprietário dos modos de produção e o respectivo trabalhador foi, historicamente, a partir do século XVIII, regulamentada pelo contrato de trabalho, de forma que o que fosse estipulado faria lei entre as partes, independentemente de seu conteúdo. Com a alta taxa de desemprego da época, os capitalistas podiam oferecer salários ínfimos, já que havia trabalhadores dispostos a aceitar qualquer condição para trabalhar. Dessa forma, a falta de limites contratuais e a miséria obrigavam o trabalhador a anuir com o que fosse oferecido para garantir seu sustento e sua sobrevivência (LUXEMBURGO, 1986). Diante das péssimas condições de vida da maioria da população, a classe trabalhadora passou a se organizar e a exigir limites e proteções no contexto da relação de trabalho. 
A coesão da organização operária estava muito associada ao sentimento de solidariedade, que uniu os trabalhadores para combater os abusos do empregador em grupos capazes de articular suas demandas - os sindicatos (LEITE, M., 1987). Assim, por meio das negociações com os empregadores e das greves, que tensionavam os governantes, houve a construção da legislação trabalhista (SILVA, 2007).

O processo de elaboração de leis que limitavam a liberdade do empregador estava e ainda está muito atrelado à ideologia, entendida como um conjunto de crenças oriundas dos interesses que estruturam a sociedade (EAGLETON, 1997). Portanto, o momento histórico de crise do Estado liberal, a miséria e o desemprego, aliados aos reflexos da 1ª Guerra Mundial (1914-1918), culminaram com a criação da Organização Internacional do Trabalho (OIT), em 1919, e determinaram os moldes usados para a criação do direito do trabalho (SILVA, 2007).

Para além de uma resposta às demandas sociais e de um modo de proteger a classe trabalhadora das arbitrariedades da burguesia, o direito do trabalho foi construído para viabilizar a sobrevivência do próprio sistema capitalista, atuando como ferramenta capaz de assegurar a dominação nas relações de produção (LOPEZ, 2001). Dessa forma, os sindicatos, ao passo que impunham limites à acumulação de capital, legitimavam a exploração da classe trabalhadora por meio de um contrato, isto é, pacificavam os ânimos "revolucionários", ajudando a manter o funcionamento do sistema (VIANA, 2004). Nesse sentido, Edelman (2016) ressalta que o sindicalismo era "atravessado pela legalidade", de forma que suas ações eram permitidas contanto que não prejudicassem o contrato de trabalho e o direito de propriedade (EDELMAN, 2016).

O direito do trabalho passou a ser regido por princípios que operam dentro da dualidade das relações de trabalho e da atuação dos sindicatos, entendida por Lopez (2001) como o caráter ambivalente ou contraditório da legislação trabalhista. Diante dessa realidade, tendo como base o princípio da proteção, cuja finalidade específica é resguardar a parte hipossuficiente da relação - a saber, o(a) trabalhador(a) -, a legislação trabalhista busca equilibrar as partes dentro da relação contratual para que possam negociar em "pé de igualdade".

A presença dos sindicatos nas negociações, de acordo com a formulação de convenções e acordos coletivos, é uma ferramenta utilizada 
para harmonizar os interesses antagônicos das duas partes da relação de trabalho. Proteções como a estabilidade do dirigente sindical, a proibição de impedir os dirigentes de exercerem sua função sindical e da discriminação dos associados à entidade, atuam para evitar a intimidação da classe operaria frente ao poder econômico de seu(ua) empregador(a).

No entanto, a contrarreforma trabalhista, expressando a ideologia da descoletivização das relações de trabalho, enfraqueceu os sindicatos profissionais e lhes retirou o patamar de igualdade, que propiciava segurança no contexto das negociações com os empregadores e sindicatos patronais, conforme será tratado no próximo capítulo.

\section{A contrarreforma trabalhista e o direito coletivo do trabalho}

A mudança no ambiente político, econômico e social experimentada pelo Brasil durante o primeiro governo petista (2003-2006) abriu uma nova estrutura de oportunidades para a ação coletiva no país e a conquista de direitos pelos trabalhadores. A retomada do crescimento econômico aliada a uma situação mais favorável do mercado de trabalho, com taxa de desemprego de 5,7\% (NOGUEIRA, 2011), permitiu a abertura de um maior espaço de discussão para que os novos problemas decorrentes das mudanças na organização da produção pudessem ser enfrentados. Assim, a criação de novos espaços destinados à participação dos atores sociais figuraria, na proposta do governo petista, em melhoria social e em geração de renda e emprego.

Dessa forma, o incentivo para a inclusão e participação dos atores sociais, em especial dos trabalhadores, revela, historicamente, que a conquista de direitos mínimos e o nascimento de garantias contra a exploração do trabalho humano foram um reflexo da capacidade de união para a defesa dos seus interesses. Contudo, essa união só reflete resultados de forma eficaz se a defesa dos interesses ocorrer em um ambiente de liberdade e com proteção dos representantes dos trabalhadores (BRITO FILHO, 2016). Para tanto, as grandes conquistas no mundo jurídico trabalhista são fundamentais, mas dependem da somatória de forças e, 
nesse sentido, é reconhecida a importância da liberdade sindical ${ }^{3}$. Impedir ou dificultar por qualquer meio a sindicalização é negar praticamente todos os mínimos direitos dos trabalhadores, pois o Estado, quando os concede, via de regra o faz pela pressão organizada e exercida pelos que vivem do trabalho e por seus representantes.

Da organização sindical decorrem os Acordos Coletivos de Trabalho (ACT) e a Convenção Coletiva de Trabalho (CCT), que, até 2017, possuíam como requisito o respeito à legislação que garantia direitos sociais ao trabalhador. Experimentava-se, então, o aumento no padrão social e econômico ou, ao menos, a preservação do patamar até então alcançado, com a possibilidade de flexibilização, em especial, da irredutibilidade salarial e da duração do trabalho. Com a vigência da Lei no 13.467/2017, denominada de Reforma Trabalhista, inaugurou-se um novo modelo para a celebração do ACT e da CCT, além da negociação coletiva de trabalho, caracterizado pela prevalência do negociado sobre o legislado.

A par disso, a contribuição sindical até então compulsória dos filiados aos respectivos sindicatos e descontada diretamente na folha de pagamento passou a contar com a exigência legal de prévia autorização expressa do trabalhador ${ }^{4}$. Essa exigência desestabilizou os sindicatos. A ausência de estrutura financeira para a sua manutenção ${ }^{5}$, após a diminuição da receita, enfraqueceu as instituições no poder de negociação coletiva ante os sindicatos patronais. Em Nota Técnica elaborada pelo Departamento Intersindical de Estatística e Estudos Socioeconômicos (DIEESE), demonstra-se que houve uma diminuição de $90 \%$ na arrecadação dos sindicatos, comparando os dados de abril de 2017 com os de abril de 2018 (DIEESE, 2018). Como repercussão do desligamento de trabalhadores dos sindicatos e da queda na receita proveniente da contribuição sindical, houve uma queda no total das negociações coletivas de 23,3\% em 2018 em

\footnotetext{
${ }^{3}$ Muito embora a unicidade sindical tenha permanecido tal como expressa na Constituição da República Federativa do Brasil de 1988 (CRFB-88).

${ }^{4}$ Anteriormente bastava a filiação sindical e o sindicato comunicava ao empregador para a realização do desconto, sem a necessidade de manifestação do trabalhador. Com a alteração legislativa, foi imposta a necessidade de autorização expressa dos trabalhadores já sindicalizados e os futuros, a fim de haver o desconto a título de contribuição sindical.

${ }^{5}$ A arrecadação sindical diminuiu 86,1\% em 2018, quando comparada com 2019 (ROUBICEK, 2019).
} 
relação a 2017. Em 2019, a queda foi de 19,4\% abaixo do total observado em 2017, segundo dados do DIEESE (2018).

A partir da vigência da Lei no $13.467 / 2017$, um novo regramento foi estabelecido para dirigir a negociação coletiva no Brasil, no qual prevalece o convencionado sobre o legislado. O rol estabelecido no artigo 611-A, além de ser meramente exemplificativo, encontra limite nas matérias elencadas no artigo $611-\mathrm{B}^{6}$, sendo a enumeração deste artigo taxativa. Com isso, inaugurou-se uma nova fase para a negociação coletiva, caracterizada pela valorização das soluções negociadas em detrimento do assegurado pela legislação heterônoma, de origem estatal e mais protetiva.

Essa alteração legislativa veio acompanhada das razões de Estado consubstanciadas no aspecto econômico nacional, na argumentação do "custo Brasil", associada aos fatores desfavoráveis à competitividade de bens e serviços brasileiros no âmbito nacional e internacional. Com relação ao "custo Brasil", em que pese a defesa dessa argumentação, ela não pode ser adotada como fundamento científico na medida em que não possui consenso sequer quanto aos dados percentuais. Todavia, essa racionalidade é própria dos regimes populistas que têm no neoliberalismo a base para provocar alterações na sociedade.

O neoliberalismo é, em primeiro lugar e fundamentalmente, uma racionalidade cujo objetivo é estruturar e organizar a ação dos governantes e da própria sociedade, e que tem a concorrência como norma de conduta para a empresa. Essa racionalidade é a razão do capitalismo contemporâneo que vem para determinar um novo modo de governo e uma nova política de Estado (DARDOT; LAVAL, 2016), incluindo aquela que intervém nos direitos trabalhistas e na representação sindical dos trabalhadores.

No contexto da alteração da Consolidação das Leis do Trabalho (CLT), percebe-se o franco ataque à manutenção dos sindicatos de trabalhadores, bem como a retirada do equilíbrio nas negociações para o estabelecimento de cláusulas convencionais, na medida em que permite, além das desconsiderações expressas no artigo 611-A, a definição de cláusulas sem a devida contrapartida para a classe trabalhadora. Portanto,

\footnotetext{
6 "Art. 611-B. Constituem objeto ilícito de convenção coletiva ou de acordo coletivo de trabalho, exclusivamente, a supressão ou a redução dos seguintes direitos: [...]”. (BRASIL, 2017, grifo nosso).
} 
a alteração da CLT, em uma perspectiva neoliberal, determina um novo tratamento para as negociações coletivas de trabalho.

Diante disso, a construção doutrinária acerca da aplicação do princípio da boa-fé apresenta uma alternativa para frear os retrocessos consequentes da contrarreforma trabalhista. Propõe-se aproveitar o movimento atual de aproximação entre o direito civil e o direito do trabalho brasileiros ${ }^{7}$ para extrair um uso combativo do princípio da boa-fé na formulação e interpretação das cláusulas que compõem os instrumentos coletivos de trabalho. Pretende-se encontrar, com a aplicação desse princípio, uma forma para o equilíbrio das cláusulas dentro do direito coletivo do trabalho, com a finalidade de fomentar o aumento da segurança jurídica e equipar os sindicatos com uma ferramenta a mais para impedir a precarização do trabalho por meio das negociações coletivas.

\section{O princípio da boa-fé e a aplicação no direito coletivo do trabalho}

Diante das recentes contrarreformas trabalhistas, o equilíbrio entre as partes vem sendo mitigado e dando margem para uma maior liberdade e autonomia na negociação coletiva, conforme a redação do artigo 611- $\mathrm{A}^{8}$, da CLT, que permite a prevalência do negociado sobre o legislado. Dessa forma, há uma aproximação entre as normativas do direito do trabalho e do direito civil, o que abre margem, também, para uma aplicação combativa do princípio geral da boa-fé como alternativa para a garantia de

\footnotetext{
7 “Art. 8․ As autoridades administrativas e a Justiça do Trabalho, na falta de disposições legais ou contratuais, decidirão, conforme o caso, pela jurisprudência, por analogia, por equidade e outros princípios e normas gerais de direito, principalmente do direito do trabalho, e, ainda, de acordo com os usos e costumes, o direito comparado, mas sempre de maneira que nenhum interesse de classe ou particular prevaleça sobre o interesse público. § $1^{\circ} \mathrm{O}$ direito comum será fonte subsidiária do direito do trabalho. (...) § 3 o No exame de convenção coletiva ou acordo coletivo de trabalho, a Justiça do Trabalho analisará exclusivamente a conformidade dos elementos essenciais do negócio jurídico, respeitado o disposto no art. 104 da Lei no 10.406, de 10 de janeiro de 2002 (Código Civil), e balizará sua atuação pelo princípio da intervenção mínima na autonomia da vontade coletiva." (BRASIL, 1943).

8 "Art. 611-A. A convenção coletiva e o acordo coletivo de trabalho têm prevalência sobre a lei quando, entre outros, dispuserem sobre: "[...] § 1ํ№ No exame da convenção coletiva ou do acordo coletivo de trabalho, a Justiça do Trabalho observará o disposto no $\S 3^{\circ}$ do art. $8^{\mathbf{o}}$ desta Consolidação. § $2 \mathrm{o}$ A inexistência de expressa indicação de contrapartida recíprocas em convenção coletiva ou acordo coletivo de trabalho não ensejará sua nulidade por não caracterizar um vício do negócio jurídico. [...].” (BRASIL, 2017).
} 
proteções, com base na ideia de equilíbrio das cláusulas das negociações e acordos coletivos de trabalho.

As formas de proteção e os limites impostos à atuação deliberada das partes são as características que distinguem os contratos de trabalho dos contratos regulamentados pelo direito civil. Todavia, este também vem desenvolvendo teorias que buscam adotar um tratamento diferenciado para sujeitos considerados "vulneráveis", como ocorre nas relações consumeristas e nas relações que envolvem menores ou incapazes. Ademais, outro mecanismo capaz de impor uma atuação pautada pela razoabilidade e pela proporcionalidade, como forma de limitar eventuais abusos do empregador dentro das relações contratuais, é a aplicação do princípio da boa-fé.

O princípio da boa-fé atua como uma "norma de conduta" e pressupõe que todos devem se comportar de acordo com um padrão ético, moral, de confiança e lealdade. Como fonte de dever instrumental do contrato, ele tem uma função reequilibradora, sendo seus deveres a lealdade, a coerência, a informação e o aviso. O dever de coerência, em especial, requer que o contrato firmado seja interpretado a partir das situações de confiança a que uma parte remete a outra, interpretação esta hermenêutico-integrativa, e "diz respeito ao papel da cláusula geral não somente como baliza para a compreensão do conteúdo do contrato interpretação em sentido estrito, mas também como padrão geral de comportamento [...]" (FRAZÃO, 2013, p. 281).

Objetiva-se que a interpretação ocorra de forma leal e atenta quanto à repercussão gerada no destinatário, conforme o artigo 113, Código Civil Brasileiro de 2002 (BRASIL, 2002): "os negócios jurídicos devem ser interpretados conforme a boa-fé, e os usos do lugar de sua celebração".

O princípio da boa-fé não fica circunscrito a um ou outro ramo do direito, mas se entrelaça com todos. Os seus valores e a confiança legítima devem ser observados pelo Estado em todas as fases das suas ações com os cidadãos, podendo a inobservância ser objeto de tutela administrativa e judicial. Constitui, também, um elemento de ordem moral essencial para o cumprimento do direito. Sem o valor do princípio da boa-fé, a maioria das normas perde seu sentido e seu significado (PLÁ RODRIGUEZ, 2015), por isso se faz essencial em todas as fases do contrato. 
Nessa perspectiva, a teoria do diálogo das fontes determina que as leis não sejam aplicadas de forma isolada, mas coexistam e incidam de forma complementar, o que viabiliza a interpretação do ordenamento jurídico como um todo unitário (MARQUES, 2004). Dessa forma, a aplicação de princípios e direitos fundamentais, de forma concomitante, colabora para garantir a máxima eficácia desses institutos. O diálogo entre o direito civil e o direito do trabalho é possível em decorrência do artigo $8^{\circ}$, § $1^{\circ}$, da CLT $^{9}$, que determina a sua aplicação subsidiária. Todavia, para além de mera fonte subsidiária, o diálogo entre ambas as matérias é recomendado por Tartuce (2013), inclusive com a aplicação direta do direito civil em determinadas questões trabalhistas.

A teoria do diálogo das fontes, portanto, adota a heterointegração das normas, que busca harmonizar os subsistemas do direito como forma de obter a máxima efetividade dos direitos fundamentais (LEITE, C., 2015). Assim, a aplicação do princípio da boa-fé no direito do trabalho e, mais especificamente, nos ACT e CCT garante a razoabilidade e a proporcionalidade dentro das relações de trabalho.

Nesse sentido, o sistema jurídico que fundamenta o direito do trabalho é aberto ou de autorreferência relativa (MAZURKEVIC, 2003), conforme o artigo $8^{\circ}$ da CLT, e tem como elemento estruturante o princípio de proteção, cuja finalidade é compensar a desigualdade verificada entre empregado e empregador. É a partir dessa ótica que o princípio da boa-fé é aplicado na esfera trabalhista.

O Código Civil Brasileiro de 1916 (CCB-1916), com perfil formalista e individualista, não possibilitava a integração com o sistema do trabalho, mas o Código Civil Brasileiro de 2002 (CCB-2002), com características de socialidade, eticidade e operabilidade, trouxe maior afinidade com a principiologia trabalhista, permitindo a complementaridade entre os sistemas jurídicos (FRAZÃO, 2013). Para Frazão (2013, p. 280), "se antes era o direito civil que podia buscar no direito do trabalho a inspiração para

\footnotetext{
9 “Art. 8․ As autoridades administrativas e a Justiça do Trabalho, na falta de disposições legais ou contratuais, decidirão, conforme o caso, pela jurisprudência, por analogia, por equidade e outros princípios e normas gerais de direito, principalmente do direito do trabalho, e, ainda, de acordo com os usos e costumes, o direito comparado, mas sempre de maneira que nenhum interesse de classe ou particular prevaleça sobre o interesse público. $§ 1^{\circ} \mathrm{O}$ direito comum será fonte subsidiária do direito do trabalho" (BRASIL, 1943).
} 
romper com o formalismo e o individualismo, hoje o último também pode se basear no primeiro para o fortalecimento e mesmo a releitura de diversos dos seus institutos".

Até 2017, eram nítidos os reflexos do princípio da boa-fé no convívio social, em especial no direito coletivo do trabalho e na negociação de cláusulas de ACT ou CCT. Atualmente, pode haver a negociação, mas com a supressão de direitos decorrentes de lei, sem haver a devida contrapartida recíproca e sem caracterizar o vício do negócio jurídico, conforme acima já indicado. A não exigência de contrapartida para os casos de estabelecimento de cláusulas não favoráveis à categoria profissional, somada ao enfraquecimento do sindicato profissional, reclama um instrumento retificador a fim de reequilibrar as forças entre o sindicato da categoria profissional e da categoria econômica, o que pode ocorrer mediante a aplicação do princípio da boa-fé.

Não por outro motivo, Ruprecht (1979, p. 219), ao tratar dos conflitos coletivos de trabalho, pondera que a negociação coletiva de trabalho, que antecede a ACT ou CCT, deve ter como requisito prévio "uma estrutura política e um grau de desenvolvimento econômico favorável à negociação coletiva e um ordenamento legal fundamental que defina claramente os direitos e obrigações mútuos dos empregadores e trabalhadores”. Para tanto, o sindicato de categoria profissional é essencial, pois "corrige os maiores defeitos do regime capitalístico e atenua as imposições da grande indústria, quase insuportáveis, e dia a dia mais vexatórias e deprimentes" (MORAES, 1986, p. 93).

Em consonância com os desenvolvimentos teóricos acima, o Tribunal Regional do trabalho da 15 ${ }^{\text {a }}$ Região (TRT15) decidiu pela aplicação do princípio da boa-fé em dissídio coletivo. Muito embora anterior à Lei no 13.467/2017, afigura-se importante a decisão no contexto da presente pesquisa:

DISPENSA COLETIVA. OBRIGATORIEDADE DA PRÉVIA NEGOCIAÇÃO DO PPE. BOA-FÉ OBJETIVA. INFORMAÇÃO PLENA. COMPENSAÇÃO FINANCEIRA. (...) 2- A negociação coletiva, à luz dos institutos da boa-fé objetiva e da transparência, não mais pode ser amesquinhada a um palco teatral com tolerância a blefes. Pelo contrário, as partes, especialmente o empregador, que detém as informações, devem colocar todas as cartas na mesa, com o objetivo da construção conjunta e madura de uma solução que responda aos seus anseios. 3O PPE (MP no 680, de 2015 e Lei no 13.189, de 19/11/2015) não prevê um 
programa de cunho individual, a ser analisado apenas sob o limitado prisma das partes. Pelo contrário, considerando inclusive a "mens legislatoris" (parecer do Relator, Deputado Federal Daniel Vilela, no sentido de que a "operação é, pois, financeiramente vantajosa para o governo, além de preservar parcialmente as estruturas de produção e de consumo, com efeitos benéficos sobre a arrecadação e o PIB"), é de interesse eminentemente público. O mesmo deve ser dito em relação ao lay off (art. 476-A, CLT). (TRT-15, 2016).

A aplicação do princípio da boa-fé, portanto, tem a função de garantir que nenhuma das partes da relação de trabalho seja lesada, em especial a classe trabalhadora, que se encontra em posição maior de vulnerabilidade, notadamente na contrarreforma trabalhista, que retirou o equilíbrio negocial do sindicato de categoria profissional ante o sindicato de categoria patronal.

\section{Considerações finais}

A relação entre o direito do trabalho e a ideologia faz com que a legislação trabalhista seja um alvo constante de tensões e embates políticos. Com a ascensão de políticas neoliberais, o direito do trabalho vem sendo objeto de contrarreformas trabalhistas, com o intuito de flexibilizar e desregulamentar direitos da classe trabalhadora, bem como mitigar a atuação dos sindicatos das categorias profissionais.

Por meio da Lei no 13.467/2017, conhecida como Reforma Trabalhista, houve o fomento de uma maior liberdade e autonomia nas negociações coletivas. Assim, alterações como a prevalência do negociado sobre o legislado, o enfraquecimento da atuação dos sindicatos, retirando sua fonte de custeio e dificultando a celebração de negociações, aproximam as normas trabalhistas das normas do direito civil.

A proposta de utilização do princípio da boa-fé como mecanismo protetivo visa garantir o equilíbrio das cláusulas nas negociações coletivas, aproveitando a aproximação das matérias para adotar um uso combativo desse princípio em prol da proteção da classe trabalhadora diante da precarização do trabalho por meio da celebração de ACT e CCT prejudiciais.

Essa aproximação pode ser encarada também com olhares positivos, permitindo a aplicação do princípio da boa-fé dentro das celebrações dos 
ACT e CCT tornadas vulneráveis pela flexibilização da contrarreforma. Dessa forma, a teoria do diálogo das fontes permite olhar o ordenamento jurídico como um todo unitário, a fim de harmonizar a aplicação das normas para garantir a máxima eficácia dos direitos fundamentais do trabalho.

\section{Referências bibliográficas}

BRASIL. Constituição da República Federativa do Brasil de 1988. Brasília, 5 out. 1988. Disponível

em: http://www.planalto.gov.br/ccivil_03/constituicao/constituicao.htm. Acesso em: 08 nov. 2020.

BRASIL. Decreto-Lei n. 5.452, de 1o de maio de 1943. Aprova a Consolidação das Leis do Trabalho. Rio de Janeiro, 1 mai. 1943. Disponível em: http://www.planalto.gov.br/ccivil_03/decreto-lei/del5452.htm. Acesso em: 08 nov. 2020.

BRASIL. Lei n. 10.406, 10 de janeiro de 2002. Institui o Código Civil. Brasília, 11 jan. $2002 . \quad$ Disponível em: http://www.planalto.gov.br/ccivil 03/Leis/2002/L10406compilada.htm. Acesso em: 08 nov. 2020.

BRASIL. Lei n. 13.467, de 13 de julho de 2017. Dispõe sobre a alteração da Consolidação das Leis do Trabalho (CLT), aprovada pelo Decreto-Lei no 5.452, de 1 o de maio de 1943, e as Leis nos 6.019, de 3 de janeiro de 1974, 8.036, de 11 de maio de 1990, e 8.212, de 24 de julho de 1991, a fim de adequar a legislação às novas relações de trabalho. Brasília, 2017. Disponível em: http://www.planalto.gov.br/ccivil 03/ Ato2015-2018/2017/Lei/L13467.htm.

Acesso em: 04 dez. 2019.

BRITO FILHO, José Cláudio Monteiro de. Trabalho decente: análise jurídica da exploração do trabalho: trabalho escravo e outras formas de trabalho indigno. 4. ed. São Paulo: LTr, 2016.

DARDOT, Pierre; LAVAL, Christian. A nova razão do mundo: ensaio sobre a sociedade neoliberal. Trad. Mariana Echalar. São Paulo: Boitempo, 2016.

DIEESE. Subsídios para o debate sobre a questão do Financiamento Sindical. Nota Técnica: no 200, dez. 2018. Disponível em:

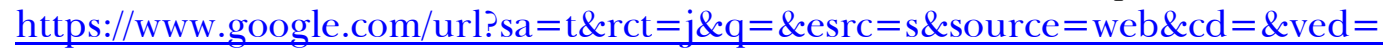
2ahUKEwi7hYSz5vPsAhWmHrkGHXuhCNUQFjAAegQIAxAC\&url=https\%3A \%2F\%2Fwww.dieese.org.br\%2Fnotatecnica\%2F2018\%2FnotaTec200financiamen toSindical.pdf\&usg =AOvVaw0rZJSVcKPxCP44m2hmm5U1. Acesso em: 08 nov. 2020.

EAGLETON, Terry. Ideologia: uma introdução. São Paulo: Unesp/Boitempo, 1997. 
EDELMAN, Bernard [1946]. A legalização da classe operária. São Paulo: Boitempo, 2016.

FRAZÃO, Ana. A boa-fé objetiva e o contrato de trabalho: as funções de criação de deveres instrumentais e de limitação ao exercício de direitos e faculdades contratuais. In: TEPEDINO, Gustavo et al. (coord.). Diálogos entre o direito do trabalho e o direito civil. São Paulo: RT, 2013. p. 295-324.

GHIRALDELLI, Reginaldo. (Contra) Reforma Trabalhista: "modernização" destrutiva no Brasil das desigualdades. Revista Libertas, Juiz de Fora, v. 19, n. 2, p. 387-407, ago./dez. 2019.

LEITE, Carlos Henrique Bezerra. As lacunas do direito e a necessidade de heterointegração (diálogo das fontes) com o direito civil. In: ALMEIDA, Renato R. (coord.). Aplicação da teoria do diálogo das fontes no direito do trabalho. São Paulo: LTr, 2015.

LEITE, Márcia de Paula. O movimento grevista no Brasil. São Paulo: Brasiliense, 1987.

LOPEZ, Manuel-Carlos Palomeque. Direito do trabalho e ideologia: meio século de formação ideológica do direito do trabalho espanhol (1873-1923). Coimbra: Almedina, 2001.

LUXEMBURGO, Rosa. Reforma social ou revolução? São Paulo: Global, 1986.

MARQUES, Cláudia Lima. Superação das antinomias pelo diálogo das fontes: o modelo brasileiro de coexistência entre o código de defesa do consumidor e o código civil de 2002. Revista da Esmese, n. 07, 2004.

MARX, Karl. O capital: crítica da economia política. 10. ed. São Paulo: Difel, 1985 .

MAZURKEVIC, Arion. A boa-fé objetiva: uma proposta para reaproximação do direito do trabalho ao direito civil. In:DALLEGRAVE NETO, José Affonso; GUNTHER, Luiz Eduardo (coords.). O impacto do novo código civil no direito do trabalho. São Paulo:LTR, 2003. p. 349-375.

MORAES, Evaristo de. Apontamentos de direito operário. 3. ed. São Paulo: LTr, 1986.

NOGUEIRA, Danielle. Lula: Brasil vive quase pleno emprego. O Globo, Rio de Janeiro, 04 nov. 2011. Disponível em: https://oglobo.globo.com/economia/lulabrasil-vive-quase-pleno-emprego-2935099. Acesso em: 09 dez. 2019.

PLÁ RODRIGUEZ, Américo. Princípios de Direito do Trabalho. 3. ed. São Paulo: LTr., 2015.

ROUBICEK, Marcelo. Acordo coletivo: como ficou 2 anos após a reforma trabalhista. Nexo Jornal, 05 nov. 2019. Disponível em: https://www.nexojornal.com.br/expresso/2019/11/05/Acordo-coletivo-como-ficou2-anos-após-a-reforma-trabalhista. Acesso em: 03 dez. 2019.

RUPRECHT, Alfredo J. Os princípios do direito do trabalho. Trad. Edilson Alkmin Cunha. São Paulo: LTr, 1995. 
. Conflitos coletivos de trabalho. Trad. José Luiz Ferreira Prunes. São Paulo: LTr/USP, 1979.

SILVA, Wanise Cabral. As fases e faces do direito do trabalho. São Paulo: LTr, 2007.

TARTUCE, Flávio. Manual de direito civil. 3. ed. Rio de Janeiro: Forense, 2013.

TRIBUNAL REGIONAL DO TRABALHO DA 15 a REGIÃO (TRT15). Dissídio Coletivo: DC 0007390572015515000. Relator: Samuel Hugo Lima. DJ: 15/02/2016. JusBrasil, 2016. Disponível em: $\underline{\text { https://rt- }}$ 15.jusbrasil.com.br/jurisprudencia/844874869/dissidio-coletivo-dc-

73905720155150000-0007390-5720155150000. Acesso em: 08 nov. 2020.

VIANA, Márcio Túlio. A reforma sindical entre o bem e o mal. Revista do Tribunal Regional do Trabalho da 3ㅜ Região, Belo Horizonte, v. 39, n. 69, p. 2336, jan./jul. 2004.

Submissão: 08 de novembro de 2020

Aceite: 31 de março de 2021

Autoria:

Ana Maria Maximiliano_anamaximil@yahoo.com.br

Mestra em Direito pela PUC/PR. Doutoranda em Direito pela Universidade Federal do Paraná (UFPR). Pesquisadora do Grupo de Estudos em Trabalho, Economia e Políticas Públicas (TRAEPP). Advogada Pública.

Isabel Ceccon Iantas isabelciantas@gmail.com

Graduanda em Direito pela Universidade Federal do Paraná (UFPR). Pesquisadora do Grupo Rede de Estudos e Monitoramento da Reforma Trabalhista (REMIR-PR).

\section{Como citar este documento:}

MAXIMILIANO, Ana Maria; IANTAS, Isabel Ceccon. A ideologia da contrarreforma do direito coletivo do trabalho e a contribuição do princípio da boa-fé para as negociações coletivas. Revista Eletrônica do CEJUR, v. 2, n. 5, set/dez 2020. doi:http://dx.doi.org/10.5380/cejur.v2i5.77774. 